\title{
Congenital Choanal Atresia - A Case Report
}

\author{
TAHMINA BEGUM ${ }^{1}$, IFFAT ARA SHAMSAD ${ }^{2}$, SAYEEDAANWAR ${ }^{3}$, SYEDAAFROZA ${ }^{4}$
}

\section{Introduction}

Choanal atresia (CA) is a rare developmental failure of the posterior nasal cavity to communicate with the nasopharyn $x^{1}$. Congenital choanal atresia was first described by Roederer in $1755^{2}$. Incidence of this developmental defect varies from 1 in 5000 to 1 in 8000 births $^{3,4}$. Bilateral atresia is more common than unilateral ${ }^{5-7}$.

Finding of cyclical cyanosis in newborn points towards the diagnosis of bilateral congenital choanal atresia.

Types of choanal atresia include bony and membranous type with bony atresia being more common $^{8}$. Approximately $10 \%$ to $50 \%$ of patients with congenital CA have additional congenital anomalies including the cluster of defects known as "CHARGE" syndrome $e^{1,3,5,6,9-16}$.

The "CHARGE" association is a poly-malformative disease associating - Coloboma, Heart disease, Atresia of choana, Retarded growth and development, Genital hypoplasia and Ear anomalies. "CHARGE" being an acronym based on these different malformations.

Data about the incidence and presentation of this congenital anomaly among Bangladeshi population is limited. In this paper, we report a unique case of bilateral congenital choanal atresia in a 2 hours old female newborn.

\section{Case Report}

A 2 hours old female newborn baby weighing $1.8 \mathrm{Kg}$ was referred from Department of Gynae and Obstetrics to the neonatal unit of the Department of Paediatrics, Dhaka Medical College Hospital for birth asphyxia. Baby was delivered by caesarian section due to prolonged $1^{\text {st }}$ stage with face presentation. On subsequent enquiry, it was found that during antenatal period, the mother was healthy and there was no history of taking any drugs.

The baby was the $1^{\text {st }}$ issue of her non consanguineous parents and family history was unremarkable.

After admission, the baby was found to have respiratory distress and cyanosis, which was relieved by crying.

1. Senior Consultant, Department of Paediatrics, $\mathrm{DMCH}$

2. Assistant Professor, Department of Paediatrics, $\mathrm{DMCH}$

3. Assistant Professor, Department of Paediatrics, DMCH

4. Professor, Department of Paediatrics, ICMH

Correspondence : Dr. Tahmina Begum
Nasogastric tube could not be passed through the nose into the nasopharynx. She did not have any other apparent problems (Fig.-1).

The baby was investigated with X-ray of the chest and posterior choanogram. Although, computed tomography (CT) accurately delineates the abnormal anatomy of the nasal fossae, it was not possible to do because of financial constraints.

However, X-ray chest was normal. On posterior choanogram, no contrast was seen in the nasopharynx, but was seen in nasal cavity, which was suggestive of bilateral choanal atresia.

Subsequently, oto-laryngologist was consulted for further management. The membrane of both choana was perforated with a urethral dilator under general anaesthesia. A plastic tube was placed in situ and fixed with silk in both nasal passages (Fig. -2).

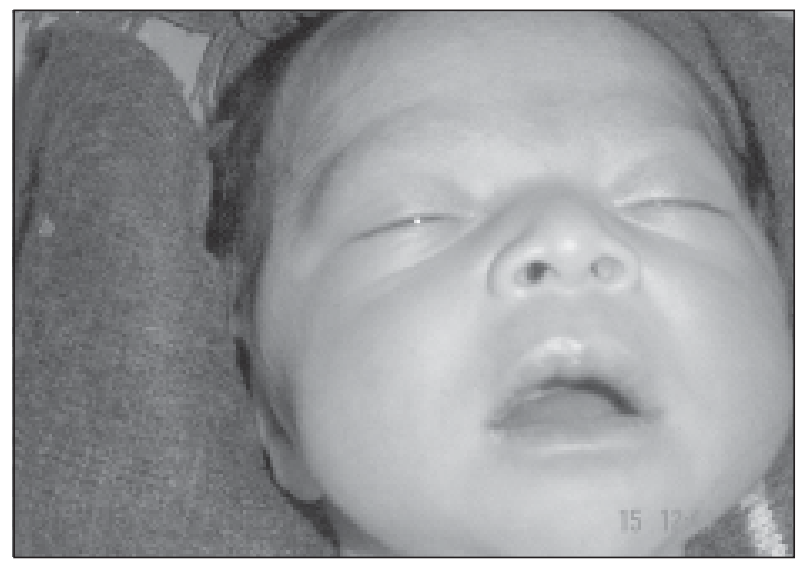

Fig.-1: Apparentlynormal babysleeping with opened mouth

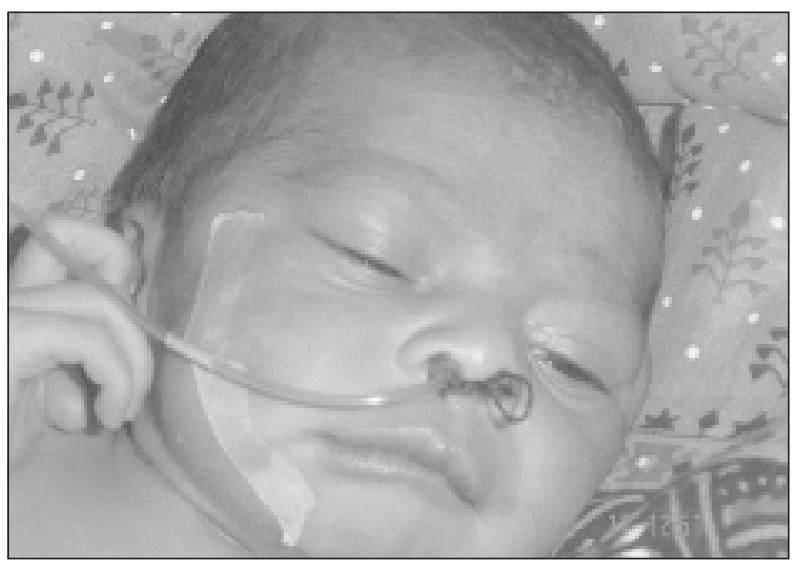

Fig.-2: After surgery plastic tube placed in situ 
Parenteral antibiotic was given in post-operative period. Irrigation of the tube was done with saline everyday to keep the tube patent and establish normal breathing. The tube was kept in situ for 2 weeks. No surgical complication was noted.

On $15^{\text {th }}$ day of operation, the baby was discharged with an advice to come after 7 days. On subsequent follow up, the baby was found normal, was gaining weight properly and did not have any breathing difficulty.

\section{Discussion}

Although the most common form of nasal obstruction in neonates is soft tissue oedema, congenital nasal deformities are being recognized as an important cause of newborn airway obstruction ${ }^{17,18}$. Choanal atresia is considered as the most common congenital anomaly of the nose ${ }^{17}$.

The incidence of CA is about $0.3 / 1000$ live birth ${ }^{19}$. There is no statistically significant difference between races in rates, even though white infants have a higher rate than those of other races ${ }^{3}$. Girls affected twice as common as boys ${ }^{19}$ which is consistent with the present case.

The genetic aspects of choanal atresia have not been clearly defined. The defect is probably a mutifactorial trait as in cleft lip and palate ${ }^{12}$. The appearance of the condition in both single and successive generations supports this contention ${ }^{20}$.

Some other authors hypothesized that the condition is of autosomal dominant inheritance with reduced penetrance ${ }^{21,22}$. They have suggested that incomplete penetrance and variable expressivity is caused by a defect of neural crest. Brenner ${ }^{18}$ reported occurrence of CA in 2 siblings and other author described a familial tendency in most of the cases of $\mathrm{CA}^{23}$. The case presented in this paper was the 1st issue of her parent and no other family member had this type of problem.

A significantly higher mean paternal age at conception together with concordance in monozygotic twins and the existence of rare familial cases support the role of genetic factors such as de novo mutation of a mutant gene or subtle submicroscopic chromosome rearrangement ${ }^{10}$. Chromosomal abnormalities were found in $6 \%$ infants with choanal atresia ${ }^{3}$. Wouters ${ }^{24}$ described partial triosomy $4 q$ and monosomy $9 p$ resulting from a familial translocation in a child with CA.
Meer $^{25}$ suggested the possibility of an undefined teratogen as an aetiologic factor for development of CA. Wilson ${ }^{26}$ reported a case of bilateral choanal atresia who had been exposed to carbimazole in utero because of maternal Grave's disease. The mother of our case was healthy and did not have any history of taking any medicine other than vitamin.

The anatomic classification of CA is commonly quoted as $90 \%$ bony and $10 \%$ membranous ${ }^{27}$. Some of the authors found that it is unilateral and complete in majority of cases ${ }^{27,28}$ but other reported bilateral atresia more frequently ${ }^{24}$ which is consistent with the present case.

Choarial atresia can occur as an isolated anomaly as in the present case but more commonly associated with one or more concomitant congenital anomalies. The anomalies may include tall forehead, maxillary hypoplasia, prognathism, microphthalmia, hypertelorism, arhinia, mandibular hypoplasia, complete absence of tongue, limb anomaly, ectodermal dysplasia, polysyndactyly and ileal atresia ${ }^{4,15,21,22,29,30 .}$

The CT plays a significant role in the diagnostic and therapeutic approach to congenital choanal atresia and should be a method of choice to evaluate neonate with nasal obstruction.

Many authors described different techniques for management of posterior choanal atresia. Joshephson ${ }^{7}$, Panwar $^{30}$ and Uri ${ }^{31}$ suggested that the repair of congenital choanal atresia using the transnasal endoscopic approach is the best method. This route offers excellent visualization of the posterior choana and hence the ability to open the defect widely with a high surgical success.

On the other hand Sadek ${ }^{23}$ and Reddy ${ }^{32}$ were in favour of another method of treatment of bilateral CA which consisted of endonasal perforation with a curved trocar. A stenting technique was followed, the aim of which was to provide good fixation, stability and easy postoperative nursing care.

Friedman ${ }^{29}$ informed that the correction can be done by a transnasal approach under endoscopic control. Straight urethral sound was used to perforate the plate. Endotracheal tube was subsequently inserted as nasal stent. Another author also supported this technique ${ }^{33}$ as it is minimally invasive and less traumatic which was applied to the present case for correction of CA. 


\section{Conclusion}

Bilateral congenital choanal atresia is a paediatric emergency and must be treated surgically. The newborn having respiratory difficulty and cyanosis at birth which is releived by crying should be suspected as a case of bilateral congenital choanal atresia. The doctors and rurses attending the newborns should be aware of this condition so that they can ensure the detection of the cases at birth and can give immediate relieve to those babies.

\section{References}

1. Naresh KP, Anil N, Srinivas S. Bilateral Congenital Choanal Atresia. Ind J Pediatr 2002; 69: 917-20.

2. Pagon RA, Zonana J, Graham JM. Coloboma, Congenital heart disease and Choanal atresia with multiple anomalies, CHARGE association. J Pediatr 1981; 99: 223-27.

3. Harris J, Robert E, Kallen B. Epidemiology of Choanal atresia with special reference to the CHARGE association. Pediatrics 1997; 99: 36367.

4. Cozzi F, Bonanni M, Cozzi DA, Orfie P, Piacenti $\mathrm{S}$. Assessment of pulmonary mechanics and breathing patterns during posturally induced glossoptosis in infants. Arch Dis Child 1996; 74 : 512-16.

5. Kallen B, Mastroiacovo P, Robort E. Major congenital malformations in Down syndrome. Am J Med Genet 1996; 65: 160-66.

6. Hsu CY, Li YW, Hsu JC. Congenital choanal atresia: Computed tomographic and clinical findings. Acta Pediatr Taiwan 1999; 40: 13-17.

7. Josephson GD, Vickery CL, Giles WC, Gross CW. Transnasal endoscopic repair of congenital choanal atresia: Long term results. Arch Otolaryngol Head-Neck Surg 1998; 124: 537-40.

8. Prescott CA. Nasal obstruction in infancy. Arch Dis Child 1995; 72: 287-89.

9. North $\mathrm{KN}, \mathrm{Wa} \mathrm{BL}, \mathrm{Cao} \mathrm{BN}$, Whiteman DA, Karf BR. CHARGE association in a child with Denovo inverted duplication. Am J Med Genet 1995; 57 : 610-14.

10. Tellier AL, Cormier DV, Abadie V, Amiel J, Sigondy S, Bonnet D et. al. CHARGE Syndrome: report of 47 cases and review. Am J Med Genet 1998; 76: 402-09.

11. Prabha PC, Hossain MJ, Bhat BV, Krishnan SG. CHARGE association- need for choanostomy. Indian Pediatr 2000; 37: 1129-33.

12. Bhattacharyya AK, Lund VJ. Unilateral choanal atresia in siblings- A rare occurence. $\mathrm{J}$ Laryngol Otol 1996; 110: 665-67.

13. Amir R, Dunham ME. Bilateral choanal atresia associated with nasal dermoid cyst and sinus: A case report and review of the literature. Am J Med Genet 1996; 61: 201.

14. Martin DM, Sheldon S, Gorski JL. CHARGE association with choanal atresia and inner ear hypoplasia in a child with a Denovo chromosome translocation. Am J Med Genet 2001; 99: 11519.

15. Prasad C, Quackenbush EJ, Whiteman D, Korf B. Limb anomalies in DeGeorge and CHARGE Syndromes. Am J Med Genet 1997; 68: 179-81.

16. Gordts F, Daele J. Endoscopic endonasal surgery in choanal atresia. Acta Pediatr Scand 2000; 54: 191-200.

17. Jones JE, Young E, Heier L. Congenital bony nasal cavity deformities. Am J Rhinol 2004; 22 : 81-86.

18. Brenner KE, Oca MJ, Donn SM. Congenital choanal atresia in sibling. J Perinatol 2000; 20: 443-44.

19. Cowen DL, Kerr AIG. Disorders of the ear, nose and throat. In: McIntosh N, Smyth PHR, editors. Forfar and Arneils Textbook of Pediatrics. $6^{\text {th }} \mathrm{ed}$. Churchill Livingstone; 2003. P. 1666.

20. Glustein J-Z, Weill M, Steinberg. Anomalies of the nipple. In additional finding in CHARGE Syndrome. Am J Med Genet 1996; 61: 201. .

21. Thiele H, Musil A, Nagel F, Majewski F. Familial arhinia, choanal atresia and microphthalmia. Am J Med Genet 1996; 63: 310-13.

22. Ramos AMA, Valiente A, Rodriguez TE, Alonso AM, Morino S, Weaver DD. Familial choanal atresia with maxillary hypoplasia, prognathism and hypodontia. Am J Med Genet 2000; 95: 23740. 
23. Sadek SA. Congenital bilateral choanal atresia. J Pediatr 1996; 128: 858-61.

24. Wouters $\mathrm{CH}$, Von Bodegam TM, Mall HA, Govaerts LC. Partial trisomy $4 q$ and monosomy $9 p$ resulting from a familial translocation in a child with choanal atresia. Ann Gent 1999; 42: 160-65.

25. Meer A, Tschopp K. Choanal atresia in premature dizygotic twins- a transnasal approach with holmium. Rhinology 2000; 38: 191-94.

26. Wilson LC, Kerr BA, Wilkinson R, Fossard C, Donnai D. Choanal atresia hypothelia following methimazole exposure in utero: a second report. Am J Med- Genet 1998; 75: 220-22.

27. Brown OE, Pownell P, Manning SC. Choanal atresia: a new anatomic classification and clinical management applications. Pediatr Rev 2000; 21: 416-20.

28. Joseph JH. Congenital disorders of the nose. In: Behrman RE, Kleegman RM, editors. Nelson
Textbook of Pediatrics. $17^{\text {th }}$ ed. Philadelphia: WB Saunders Company; 2004. P. 1386-87.

29. Friedman NR, Mitchell RB, Bailey CM, Albert DM, Leighton SE. Management and outcome of choanal atresia correction. Pediatr Rev 1995; 16: 475-76.

30. Panwar SS, Martin FW. Transnasal endoscopic holmium YAG laser correction of choanal atresia. J Laryngol Otol 1996; 110: 429-31.

31. Uri N, Greenberg E. Endoscopic repair of choanal atresia: practical operative technique. Am J Otolaryngo 2004; 32: 125-27.

32. Reddy TN, Dutt SN, Raza M. Emergency management of bilateral choanal atresia in the newborn by the endoscopic endonasal approach: a clinical record and review of literature. Int $\mathrm{J}$ Pediatr Otorhinolaryngol 1996; 38: 21-30.

33. Caversaccio M, Hausler R. Unilateral choanal atresia: A possible indication of computer aided surgery. A report of 2 cases. Rhinology 2000; 38: 93-95. 